\title{
World Journal of Study of risk factors for intraoperative
Pediatric Surgery hypothermia during pediatric burn surgery
}

Yaoqin $\mathrm{Hu},{ }^{1}$ Yangfan Tian, ${ }^{2}$ Manqing Zhang, ${ }^{1}$ Jialian Zhao, ${ }^{1}$ Qiang $S h{ }^{2}$

To cite: Hu Y, Tian Y, Zhang M, et al. Study of risk factors for intraoperative hypothermia during pediatric burn surgery. World $\mathrm{Jnl}$ Ped Surgery 2021;4:e000141. doi:10.1136/wjps-2020-000141

Received 30 April 2020 Revised 27 December 2020 Accepted 28 December 2020

Check for updates

(c) Author(s) (or their employer(s)) 2021. Re-use permitted under CC BY-NC. No commercial re-use. See rights and permissions. Published by BMJ.

${ }^{1}$ Department of Anesthesiology, Children's Hospital, Zhejiang University School of Medicine, Hangzhou, China

${ }^{2}$ Cardiothoracic Surgery, Children's Hospital, Zhejiang University School of Medicine, Hangzhou, China

Correspondence to Dr Qiang Shu; shuqiang@zju. edu.cn

\section{ABSTRACT}

Background Intraoperative hypothermia (core temperature $<36.0^{\circ} \mathrm{C}$ ) is common during the perioperative period and can result in adverse consequences, especially in children. We aimed to determine the incidence of intraoperative hypothermia and its risk factors in pediatric patients during burn surgery.

Methods In the present study we enrolled 197 pediatric patients with burn injury undergoing surgical debridement and skin grafting. Factors, such as total burn surface area (TBSA), were collected and analyzed to identify the potential risk factors for intraoperative hypothermia. Results The incidence of intraoperative hypothermia among all patients was $17.8 \%$. Compared with patients with normothermia, children with hypothermia were associated with larger TBSA ( $25 \%$ vs $15 \%, p<0.001)$ and with less intraoperative active warming ( $34.28 \%$ vs $54.93 \%$, $p<0.05$ ). In addition, compared with patients with moderate-degree burn, patients with severe and extremely severe burn were associated with much higher risk of intraoperative hypothermia [severe: odds ratio $(\mathrm{OR})=3.805,95 \%$ confidence interval $(\mathrm{Cl})=1.396-10.368, \mathrm{p}=0.009$; extremely severe: $\mathrm{OR}=6.933,95 \% \mathrm{Cl}=2.604-18.462, \mathrm{p}<0.001]$. TBSA was the only independent risk factor that emerged as being strongly associated with intraoperative hypothermia $(\mathrm{OR}=1.068$, $p=0.001$ ) and could be used to predict the occurrence of hypothermia when combined with other factors. TBSA for predicting intraoperative hypothermia by receiver operating characteristic (ROC) curve analysis showed a good predictive ability with an area under the ROC curve of 0.758 .

Conclusion TBSA is an important risk factor for intraoperative hypothermia in pediatric patients with burn.

\section{INTRODUCTION}

Hypothermia, which is clinically defined as a core body temperature less than $36^{\circ} \mathrm{C}$, is common in patients during surgical anesthesia. ${ }^{1}$ Hypothermia is associated with numerous adverse consequences ${ }^{2}$ including prolonged stay in the recovery room and hospital, ${ }^{3}$ increased intraoperative blood loss and transfusions, ${ }^{4}$ cold-induced coagulation dysfunction, ${ }^{5}$ and postoperative infection. ${ }^{6}$ The incidence of hypothermia is reported to be between $4 \%$ and $72 \%^{7}$ or even up to $90 \%$ in adult patients. ${ }^{8}$ Infants and neonates are at an increased risk for perioperative hypothermia due to heat loss resulting from an
Key messages

What is already known about this subject?

- Intraoperative hypothermia is a common complication after burn surgery.

- The incidence of hypothermia fluctuates greatly. Perioperative hypothermia occurs in up to $50 \%$ of the pediatric population.

- Total burn surface area is the main risk factor for intraoperative hypothermia among patients with pediatric burn.

- Following the rules of standard operation procedure (SOP) strictly can reduce the incidence of intraoperative hypothermia.

\section{What are the new findings in this paper?}

- The present study showed a low frequency of intraoperative hypothermia $(17.8 \%)$ in pediatric surgery cases with burn injury.

- Whether to use SOP was an important point to prevent intraoperative hypothermia. More intraoperative hypothermia occurred without using a warm touch system even in older group.

- The incidence of intraoperative hypothermia was higher in children between 1 and 3 years than that in infants under 1 year old without using a warm touch system.

How might it impact on clinical practice in the foreseeable future?

- Carrying out SOP can effectively prevent the occurrence of intraoperative hypothermia in burned children.

- Focusing on doctors' training is also an important part to prevent intraoperative hypothermia.

increased surface area to body weight ratio and less subcutaneous fat. ${ }^{9}$ Recent studies indicate that intraoperative warming successfully reduces the risk of hypothermia and its consequences. ${ }^{10-13}$ However, limited data are available regarding perioperative hypothermia and its relationship to outcomes in the pediatric population. Our study aimed to determine the overall incidence of intraoperative hypothermia and its associated risk factors in pediatric patients with burn. 


\section{METHODS}

\section{Patients}

In this study, we enrolled 197 pediatric patients with burn who underwent debridement and skin grafting surgery from 1 October 2017 to 1 October 2018. The characteristics and perioperative data of these children were collected and analyzed for the risk factors for intraoperative hypothermia.

\section{Inclusion and exclusion criteria}

The inclusion criteria contained children with burn undergoing debridement and skin grafting from 1 October 2017 to 1 October 2018, who aged 1 hour to 14 years with normal body temperature before surgery. Exclusion criteria were chilren with fever due to infection or other reasons within 3 days before surgery, or with low preoperative body temperature $\left(<36.0^{\circ} \mathrm{C}\right)$, or with abnormal temperature regulation such as malignant hyperthermia and malignant syndrome; hyperthyroidism, hypothyroidism or other endocrine disease affecting body temperature; or who underwent cardiac surgery and other condition that required therapeutic hypothermia; or who had perioperative use of drugs that affected body temperature, such as Tylenol. Standard operation procedure (SOP) in the hospital is as follows: the theater, which is draft free, should be warmed to a temperature of $22^{\circ} \mathrm{C}-25^{\circ} \mathrm{C}$. For children with severe burns and hypothermia before surgery, we set the operating room temperature at $26^{\circ} \mathrm{C}-27^{\circ} \mathrm{C}$. The temperature in the operating room was controlled within the specified range of SOP. The assessment of the exposed area of the body surface was according to the Chinese new nine dividing method to assess the burn area. The exposed area of the body surface during the operation was defined as the area of exposed skin after the spread. We used preheated infusion and disinfectant, sterile drapes to cover the burned body and a blanket to keep patients warm. Active warming in this article is to specifically use the patient warming system (WarmTouch).

A total of 222 patients with burn surgery were considered in this study. Among these, 25 patients were excluded for either hypothermia or fever preoperatively.

\section{Anesthesia and body temperature monitor}

After entering the operating room, routine monitoring criteria, such as blood oxygen saturation $\left(\mathrm{SpO}_{2}\right)$, electrocardiogram (ECG), automated non-invasive blood pressure or invasive blood pressure, were measured. The esophageal temperature was monitored after anesthesia induction or intubation. The anesthesia induction program included midazolam $0.1 \mathrm{mg} / \mathrm{kg}$, propofol $2 \mathrm{mg}$ / $\mathrm{kg}$, fentanyl $5-10 \mu \mathrm{g} / \mathrm{kg}$ and rocuronium $0.6-1 \mathrm{mg} / \mathrm{kg}$. Anesthesia maintenance was with propofol $[100-200 \mu \mathrm{g} /$ $(\mathrm{kg} \cdot \mathrm{min})]$ and remifentanil $[0.5-1.5 \mu \mathrm{g} /(\mathrm{kg} \cdot \mathrm{min})]$ intravenous pumping or sevoflurane $(1 \%-2 \%)$ inhalation.

\section{Data collection}

Preoperative data, such as age, gender, weight, burn area, preoperative body temperature, American Society of Anesthesiologists grade, and comorbidities, were collected. Burn degree was categorized into four levels according to its severity of area. Mild burn was defined as the area of degree II burn less than $5 \%$, and moderate burn was the area of degree II burn between $6 \%$ and $15 \%$ or the degree III burn less than $5 \%$. Severe burn was defined as the area of degree II burn between $16 \%$ and $25 \%$ or the degree III burn $6 \%-10 \%$, whereas an extremely severe burn was the area of degree II burn more than $25 \%$ or the degree III $>10 \% .{ }^{14}$ Children included in the study were patients with moderate or severe or extremely severe burn. Intraoperative factors, such as anesthesia and surgical methods, anesthesia time, operation time blood transfusion, infusion volume, urine output and active body warming, were collected. Other parameters included intensive care unit admission.

\section{Statistical analyses}

Continuous variables were summarized using mean and standard deviation (SD) under normal distribution, such as body weight, or median and interquartile range (IQR) when they are not normally distributed. A t-test or Mann-Whitney U test or a $\chi^{2}$ test was used to compare the difference between the groups using SPSS V.20.0 software (SPSS). Variables associated with intraoperative hypothermia at a $\mathrm{p}$ value less than 0.2 were included as potential independent risk factors for multivariable logistic regression analysis. Binary logistic regression analysis was used to identify significant risk factors for intraoperative hypothermia and to establish a predictive model. The predictive value was assessed using a receiver operating characteristic (ROC) curve. An area under the ROC curve (AUC) $>0.75$ was considered to be a good predictor. The significance level of the hypothesis tests was set at 0.05 .

\section{RESULTS}

Basic characteristics and intraoperative factors between patients with intraoperative hypothermia and controls

In the study, we enrolled a total of 197 infants and children who underwent debridement and skin grafting surgery during the 1-year period. Intraoperative hypothermia occurred in 35 cases $(17.8 \%)$. Patients aged $>3$ years had significantly higher risk of intraoperative hypothermia than those aged $\leq 3$ years $(p=0.014)$. In contrast, intraoperative hypothermia was significantly lower in children aged 1-3 years than that in those aged less than 1 year or over than 3 years $(p=0.026)$, and no significant difference was noted between infants aged 1 day to 1 year old and those aged less than 1 year $(\mathrm{p}=0.689)$. Patients who received intraoperative active warming had lower risk of intraoperative hypothermia than those without active warming $(34.28 \%$ vs $54.93 \%, \mathrm{p}=0.027)$. Patients in hypothermia group received $21.13 \mathrm{~mL} / \mathrm{kg}$ of fluid 
Table 1 Basic characteristic and intraoperative factors between patients with and without intraoperative hypothermia

\begin{tabular}{|c|c|c|c|}
\hline Basic characteristics & $\begin{array}{l}\text { Hypothermia } \\
(n=35)\end{array}$ & $\begin{array}{l}\text { Without hypothermia } \\
(n=162)\end{array}$ & $P$ value \\
\hline $\mathrm{Age}^{\star}, \mathrm{n}(\%)$ & & & $0.027 \S$ \\
\hline $1 \mathrm{~d}$ to $1 \mathrm{y}$ & $10(28.6)$ & $41(24.7)$ & 0.689 \\
\hline $1-3 y$ & $14(40)$ & $98(60.1)$ & 0.026 \\
\hline$>3 y$ & $11(31.4)$ & $23(14.2)$ & 0.014 \\
\hline Gender (male) ${ }^{\star}, \mathrm{n}(\%)$ & $17(48.57)$ & $98(60.49)$ & 0.194 \\
\hline Body weight† $(\mathrm{kg})$ & $13.66 \pm 8.14$ & $12.68 \pm 6.66$ & 0.214 \\
\hline Duration of operation $\ddagger$ (min) & $85(60-135)$ & $73(56-110)$ & 0.155 \\
\hline Volume of intraoperative intravenous (infusion) fluid $\dagger(\mathrm{mL} / \mathrm{kg}$ ) & $21.13 \pm 16.74$ & $16.61 \pm 11.59$ & 0.136 \\
\hline Patient receiving intraoperative active warming ${ }^{*}, \mathrm{n}(\%)$ & $12(34.28)$ & $89(54.93)$ & 0.027 \\
\hline Mode of anesthesia*, n (\%) & & & 0.38 \\
\hline General & $32(91.43)$ & 136 (83.95) & \\
\hline General+regional & $3(8.57)$ & $26(16.05)$ & \\
\hline TBSA (\%), median (IQR)‡ & $25(20-35)$ & $15(10-25)$ & $<0.001$ \\
\hline
\end{tabular}

Data are presented as $\mathrm{n}((\%)$ or mean $\pm \mathrm{SD}$.

The active warming in this text is to specifically use the patient warming system (WarmTouch).

$P$ values in bold are considered statistically significant.

${ }^{*} P$ values obtained by $\chi^{2}$ test.

$\dagger P$ values obtained by t-test.

$\ddagger P$ value obtained by Mann-Whitney $U$ test.

$\S P$ value was calculated by $\chi^{2}$ test among three age groups.

IV, intravenous infusion; SD, standard deviation; TBSA, total burn surface area.

infusion compared with $16.61 \mathrm{~mL} / \mathrm{kg}$ in the normothermia group; however, this difference was not statistically significant $(\mathrm{p}=0.136)$. Other variables, such as gender, body weight, duration of operation and mode of anesthesia, showed no statistically significant difference between the two groups of patients. Detailed characteristics of patients with hypothermia or normothermia are summarized in table 1.

Age distribution of patients receiving intraoperative active warming and intraoperative hypothermia

We analysed the age distribution between patients with or without intraoperative active warming. The propotion of intraoperative hypothermia was quite different among the three age groups. Infants aged 1 day to 1 year received significantly more intraoperative active warming than those aged over 1 year $(p<0.001)$, and children over 3 years old received significantly less intraoperative active warming than those younger than 3 years $(p<0.001)$. There was no difference in the propotion of intraoperative active warming between patents aged 1-3 years old and those younger than 1 year or over 3 years $(p=0.650)$ (table 2). This association explains the age-specific differences in intraoperative hypothermia.

\section{Degree of burn and intraoperative hypothermia}

Total burn surface area (TBSA) in patients with intraoperative hypothermia ranged from $10 \%$ to $56 \%$ with a median of $25 \%$ (IQR $=20 \%-35 \%)$. In contrast, TBSA in patients without hypothermia ranged from 6\% to
$60 \%$ with a median of $15 \%(\mathrm{IQR}=10 \%-25 \%, \mathrm{p}<0.001)$ (table 1). Twenty percent of patients with moderate burn were hypothermic, compared with $34.28 \%$ of patients with severe burn and $45.71 \%$ of patients with extremely severe burn. Compared with patients with moderate burn, both patients with severe burn and extremely severe burn had significantly higher risk of intraoperative hypothermia $(\mathrm{OR}=3.805, \mathrm{p}=0.009$ and $\mathrm{OR}=6.933$, $\mathrm{p}<0.001$, respectively) (table 3 ).

\section{Multivariable factors and the predictive model}

Multivariable binary logistic regression was used to identify risk factors from gender, TBSA, duration of operation, perioperative intravenous fluid and age above 3 years and intraoperative active warming. The combination of age $>3$ years and receiving intraoperative active warming was

Table 2 Age distribution of patients receiving intraoperative active warming

\section{Intraoperative active} warming

\begin{tabular}{lccc}
\cline { 2 - 3 } Age distribution & No $(\mathbf{n}=96)$ & Yes $(\mathbf{n}=101)$ & P value \\
\hline $1 \mathrm{~d}$ to 1 y & $14(14.58)$ & $37(36.63)$ & $<0.001$ \\
$1-3$ y & $53(55.21)$ & $59(58.42)$ & 0.650 \\
$>3 \mathrm{y}$ & $29(30.21)$ & $5(4.95)$ & $<0.001$ \\
\hline
\end{tabular}

Data are presented as $\mathrm{n}(\%)$.

$P$ values are obtained by $\chi^{2}$ test.

$P$ values in bold are considered statistically significant. 


\begin{tabular}{lcllr}
\hline \multicolumn{2}{l}{ Table 3} & TBSA and intraoperative hypothermia & & \\
\hline TBSA & Hypothermia $(\mathbf{n}=\mathbf{3 5})$ & Without hypothermia $\mathbf{( n = 1 6 2 )}$ & OR (95\% Cl) & P value \\
\hline Moderate & $7(20)$ & $91(56.17)$ & 1.0 & \\
Severe & $12(34.28)$ & $41(25.31)$ & $3.805(1.396$ to 10.368$)$ & 0.009 \\
Extremely severe & $16(45.71)$ & $30(18.52)$ & $6.933(2.604$ to 18.462$)$ & $<0.001$ \\
\hline
\end{tabular}

Data are presented as $\mathrm{n}(\%)$.

$P$ values obtained by $\chi^{2}$ test.

$\mathrm{Cl}$, confidence interval; IQR, Inter quartile range; OR, odds ratio; TBSA, total burn surface area.

not a significant risk factor $(\mathrm{p}=0.169)$. After multivariable regression analysis, TBSA was found to be the only independent risk factor that emerged as being strongly associated with intraoperative hypothermia $(\mathrm{OR}=1.068$, $\mathrm{p}=0.001$ ) (table 4). The performance of TBSA for predicting intraoperative hypothermia was evaluated by ROC curve analysis. The model showed good predictive ability with an AUC of 0.758 (95\% CI $=0.670-0.846)$; however, the AUC based on a model with TBSA alone was $0.723(95 \%$ CI $=0.32-0.814)$ (figure 1$)$.

\section{DISCUSSION}

Burn injury is one of the leading causes of morbidity and mortality in children. Intraoperative hypothermia is a common and preventable complication during burn surgery. ${ }^{1516}$ Children are prone to hypothermia during burn surgery due to underdeveloped thermogenic capacity, ${ }^{7}$ larger body surface area to body mass ratio, and thinner insulating subcutaneous tissue.

As the body loses its heat-generating function under anesthesia, the ambient temperature in the operating room will significantly affect the perioperative temperature in children. Ideally, the ambient temperature in the operating room should make all personnel in the operating room (especially the patient) feel comfortable, and the operating room temperature should not become a risk factor for complications of surgery or anesthesia. However, the actual situation is not the case. The operating

\begin{tabular}{lll}
\hline $\begin{array}{l}\text { Table } 4 \\
\text { hypothermia }\end{array}$ & Risk factors associated with intraoperative \\
\hline Risk factors & OR (95\% Cl) & P value \\
\hline Gender (male) & $2.110(0.922$ to 4.830$)$ & 0.077 \\
\hline TBSA & $1.068(1.029$ to 1.109$)$ & $\mathbf{0 . 0 0 1}$ \\
\hline Duration of operation & $0.992(0.981$ to 1.004$)$ & 0.181 \\
$\begin{array}{l}\text { Perioperative intravenous } \\
\text { (infusion) fluid }\end{array}$ & $1.031(0.996$ to 1.066$)$ & 0.080 \\
$\begin{array}{l}\text { Age }>3 y \text { and patient } \\
\text { receiving intraoperative } \\
\text { active warming }\end{array}$ & $4.351(0.535$ to 35.360) & 0.169 \\
\hline
\end{tabular}

$P$ values are obtained by multivariable logistic regression analysis.

$P$ values in bold are considered statistically significant. $\mathrm{Cl}$, confidence interval; IV, intravenous infusion; OR, odds ratio; TBSA, total burn surface area. room temperature is approximately the same all over the world, between $18^{\circ} \mathrm{C}$ and $24^{\circ} \mathrm{C}$. The low temperature in the operating room can aggravate the loss of body heat in children throughout the entire anesthesia and surgery process. Even though we increase the room temperature up to $27^{\circ} \mathrm{C}$, little patients with severe burn are still likely to get hypothermia during the surgery.

The present study showed a low frequency of intraoperative hypothermia $(17.8 \%)$ in pediatric cases with burn injury during surgery. A previous study reported a high incidence of perioperative hypothermia (up to 50\%) in a pediatric population. ${ }^{17}$ TBSA is the main risk factor for intraoperative hypothermia among pediatric patients with burn and can be used to predict the occurrence of hypothermia when combined with other intraoperative factors. After burn injury, normal skin tissue is destroyed, which accelerates the water and heat loss and makes patients more susceptible to intraoperative hypothermia. Under normal circumstances, the changes in patient's body temperature during the perioperative period can be categorized into three stages: a rapid decline phase, a linear decline phase and a plateau phase. However, the three stages of body temperature change are not absolutely fixed and can change with the application of body temperature interventions during the perioperative

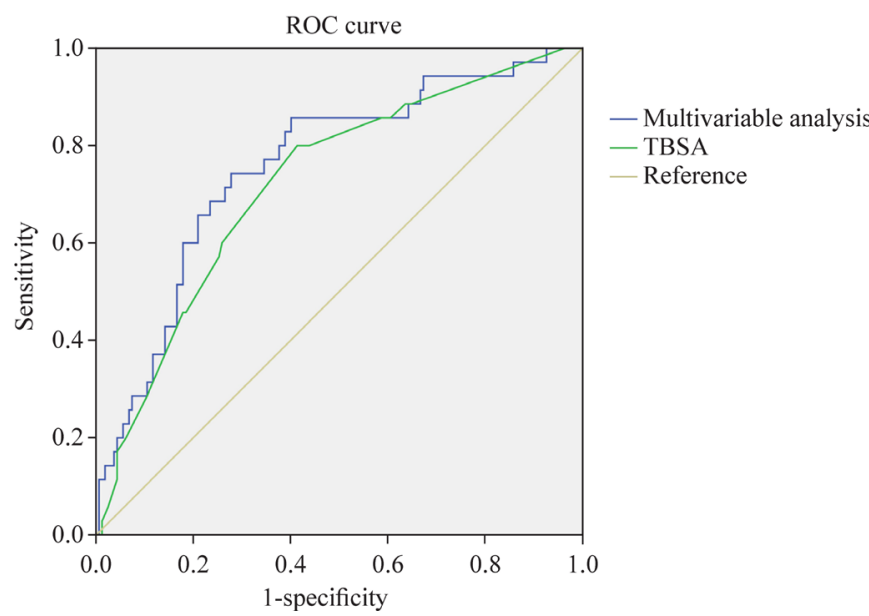

Figure 1 Receiver operating characteristic (ROC) curves based on risk factors and respective area under the ROC curves (AUCs). The blue ROC curve was based on all the potential risk factors used in multivariable logistic regression with model, whereas the green curve was computed using total burn surface area (TBSA) as the only factor. 
period. Therefore, patients should be monitored closely for core body temperature during or even before surgery. We also found that the intraoperative active warming was beneficial and was associated with lower incidence of intraoperative hypothermia. Nevertheless, there are only two machines of warming system working for all the patients of 18 operating rooms, so the demand for these machines among all patients with hypothermia intraoperatively can not be met. Active warming may make it possible to prevent hypothermia during the operation and to reduce risk of postoperative morbidity, which is significant for enhanced recovery after surgery. ${ }^{18}$ Furthermore, Rogers et al suggested that hypothermia during operation could be ameliorated by active intraoperative practices and preoperative interventions. ${ }^{19}$ Age and weight were important predictors in other studies ${ }^{20} 21$ as the physiological condition of the human body and the role of fat itself were likely to be as a thermal insulator. In the present study, there were no significant differences in other factors, such as age, weight, and operation time, partly due to use of active warming. Our center gives variable findings, considering some factors as the role of marks, such as the TBSA of pediatric patients, and active warming.

Previous studies demonstrated that infants and neonates had an increased risk for developing perioperative hypothermia. ${ }^{722}$ Their rate of heat loss is greater due to lean body and to increased surface area to body weight ratio. In addition, their thermoregulatory capacity is less effective. Our study found that hypothermia was less occured in patients aged 1-3 years old. However, there was an opposite result in children over 3 years old due in part to lack of active warming in the older group (age $>3$ years). Infants (aged 1 day to 1 year) received more intraoperative active warming. Hypothermia was associated with less intraoperative active warming, which also was reported previously. ${ }^{23}$ Intraoperative hypothermia (central temperature $<36.0^{\circ} \mathrm{C}$ ) is usually preventable, and it is important to increase the awareness of intraoperative insulation. Additionally, more attention should be given to little infants to avoid hypothermia.

As for the high incidence of intraoperative hypothermia, there are several areas that need improvement, including the increased use of active warming techniques, continuous monitoring of core temperature during operation, and increased vigilance. The findings of our study may contribute to the limited literature about specific predictors of intraoperative hypothermia for burn victims in children. While burn injury puts susceptible children at considerable risk of hypothermia, applying a preventive strategy is very important because a patient's age, total burn extent and presence of full-thickness burns are also independent factors for mortality. ${ }^{24} 25$

In conclusion, the incidence of intraoperative hypothermia in children during burn surgery was approximately $17.8 \%$ in this retrospective study, which was lower than that reported in previous studies. Warm touch system in SOP intraoperative is necessary for the patients with hypothermia. TBSA is a risk factor and predictor for intraoperative hypothermia. One of the limiations of this study is that we only investigated hypothermia in children with burnfor 12 months in this paper. The results may be biased given the limited number of cases. A larger number ofpatients are needed for further investigations.

Acknowledgements The authors thank Professor Daqing Ma for his critical comments during manuscript preparation.

Contributors HYQ contributed to writing - original draft and data curation. TYF contributed to writing - review \& editing. ZMQ contributed to data curation. ZJL contributed to formal analysis. SQ contributed to conceptualization and supervision.

Funding This work was supported by the Natural Science Foundation of Zhejiang Province (grant number LY20H100005)

Competing interests None declared.

Patient consent for publication Not required.

Ethics approval This retrospective study was conducted at the Children's Hospital of Zhejiang University School of Medicine after approval from the hospital ethics committee (2019-IRB-019) and was registered in the Chinese Clinical Trial Registry with trial registration number of ChiCTR 1900026060

Provenance and peer review Not commissioned; externally peer reviewed.

Data availability statement All data relevant to the study are included in the article or uploaded as supplementary information.

Open access This is an open access article distributed in accordance with the Creative Commons Attribution Non Commercial (CC BY-NC 4.0) license, which permits others to distribute, remix, adapt, build upon this work non-commercially, and license their derivative works on different terms, provided the original work is properly cited, appropriate credit is given, any changes made indicated, and the use is non-commercial. See: http://creativecommons.org/licenses/by-nc/4.0/.

\section{REFERENCES}

1 Sessler DI. Perioperative thermoregulation and heat balance. Lancet 2016;387:2655-64.

2 Long KC, Tanner EJ, Frey M, et al. Intraoperative hypothermia during primary surgical cytoreduction for advanced ovarian cancer: risk factors and associations with postoperative morbidity. Gynecol Oncol 2013;131:525-30.

3 Anderson SW, Todd MM, Hindman BJ, et al. Effects of intraoperative hypothermia on neuropsychological outcomes after intracranial aneurysm surgery. Ann Neurol 2006;60:518-27.

4 Rajagopalan S, Mascha E, Na J, et al. The effects of mild perioperative hypothermia on blood loss and transfusion requirement. Anesthesiology 2008;108:71-7.

5 Fuernau G, Beck J, Desch S, et al. Mild hypothermia in cardiogenic shock complicating myocardial infarction. Circulation 2019;139:448-57.

6 Baucom RB, Phillips SE, Ehrenfeld JM, et al. Association of perioperative hypothermia during colectomy with surgical site infection. JAMA Surg 2015;150:570-5.

7 Burns SM, Piotrowski K, Caraffa G, et al. Incidence of postoperative hypothermia and the relationship to clinical variables. J Perianesth Nurs 2010;25:286-9.

8 Burger L, Fitzpatrick J. Prevention of inadvertent perioperative hypothermia. Br J Nurs 2009;18:1114-9.

9 Tander B, Baris S, Karakaya D, et al. Risk factors influencing inadvertent hypothermia in infants and neonates during anesthesia. Paediatr Anaesth 2005;15:574-9.

10 Mehta $\mathrm{OH}$, Barclay KL. Perioperative hypothermia in patients undergoing major colorectal surgery. ANZ J Surg 2014;84:550-5.

11 Grote R, Wetz A, Bräuer A, et al. Short interruptions between pre-warming and intraoperative warming are associated with low intraoperative hypothermia rates. Acta Anaesthesiol Scand 2020;64:489-93.

12 Lau A, Lowlaavar N, Cooke EM, et al. Effect of preoperative warming on intraoperative hypothermia: a randomized-controlled trial. Can J Anaesth 2018;65:1029-40.

13 Ralte P, Mateu-Torres F, Winton J, et al. Prevention of perioperative hypothermia: a prospective, randomized, controlled trial of Bair Hugger versus Inditherm in patients undergoing elective arthroscopic shoulder surgery. Arthroscopy 2020;36:347-52. 
14 Rickard RF, Martin NAJ, Lundy JB. Imprecision in TBSA calculation. Burns 2014;40:172-3.

15 Haydar B, Baetzel A, Elliott A, et al. Adverse events during intrahospital transport of critically ill children: a systematic review. Anesth Analg 2020;131:1135-45.

16 Mutchnick I, Thatikunta M, Braun J, et al. Protocol-driven prevention of perioperative hypothermia in the pediatric neurosurgical population. J Neurosurg Pediatr 2020:548-54.

17 Schur MD, Blumstein GW, Seehausen DA, et al. Intraoperative hypothermia is common, but not associated with blood loss or transfusion in pediatric posterior spinal fusion. $J$ Pediatr Orthop 2018;38:450-4.

18 Bayter-Marin JE, Cárdenas-Camarena L, Durán H, et al. Effects of thermal protection in patients undergoing body contouring procedures: a controlled clinical trial. Aesthet Surg J 2018;38:448-56

19 Rogers AD, Saggaf M, Ziolkowski N. A quality improvement project incorporating preoperative warming to prevent perioperative hypothermia in major burns. Burns 2018;44:1279-86.
20 Gala T, Shahzad N, Edhi Al, et al. Perioperative hypothermia in colorectal surgeries: are we doing enough to prevent it? J Pak Med Assoc 2020;70:304-7.

21 Shahzad NAA, lqbal R. Obesity and the outcome of surgical intensive care unit patients: a prospective cohort study. Clin Surg 2018:1-9.

22 Hart SR, Bordes B, Hart J, et al. Unintended perioperative hypothermia. Ochsner J 2011;11:259-70.

23 Yi J, Lei Y, Xu S, et al. Intraoperative hypothermia and its clinical outcomes in patients undergoing general anesthesia: national study in China. PLoS One 2017;12:e0177221.

24 Ziegler B, Kenngott T, Fischer S, et al. Early hypothermia as risk factor in severely burned patients: a retrospective outcome study. Burns 2019;45:1895-900.

25 Weaver MD, Rittenberger JC, Patterson PD, et al. Risk factors for hypothermia in EMS-treated burn patients. Prehosp Emerg Care 2014;18:335-41. 